\title{
A PERCEPÇÃO DOS DISCENTES DO CURSO TÉCNICO EM MINERAÇÃO DO INSTITUTO FEDERAL DO AMAPÁ, CAMPUS MACAPÁ, SOBRE EDUCAÇÃO AMBIENTAL
}

\author{
Francisco Daniel Soares ${ }^{1}$ \\ Joádson Rodrigues da Silva Freitas²
}

Resumo: Este estudo teve por objetivo analisar a percepção dos discentes do curso técnico em mineração do Instituto Federal do Amapá, sobre a Educação Ambiental. Os dados foram obtidos por meio de aplicação de questionário online, através da ferramenta google forms, participaram da pesquisa 37 alunos, $43,2 \%$ do sexo masculino e $56,8 \%$ do feminino, todos concluintes e regularmente matriculados no ano letivo de 2017. A pesquisa mostrou que os estudantes, possuem entendimento acerca da dinâmica de interação que ocorre entre o homem e a natureza. Observou-se, que os discentes possuem um repertório de conhecimentos acerca das questões relacionadas ao meio ambiente, e que os mesmos entendem a importância da Educação Ambiental para a sua futura área de atuação profissional, tendo em vista que o setor mineral possui forte potencial de impactar o meio ambiente.

Palavras-chave: Educação Ambiental; Instituto Federal do Amapá; Mineração; Percepção Ambiental. 
Abstract: This study aimed to analyze the perception of students of the technical course in mining at the Federal Institute of Amapá, about Environmental Education. The data were obtained through the application of an online questionnaire, using the Google Forms tool. 37 students participated in the survey, $43.2 \%$ male and $56.8 \%$ female, all graduating and regularly enrolled in the 2017 school year. Research has shown that students have an understanding of the interaction dynamics that occur between man and nature. It was observed that the students have a repertoire of knowledge about issues related to the environment, and that they understand the importance of Environmental Education for their future area of professional activity, considering that the mineral sector has a strong potential for impact the environment.

Key words: Environmental Education; Federal Institute of Amapá; Mining; Environmental Perception

\section{Introdução}

As questões relacionadas com a temática ambiental tornaram-se mais intensas no decorrer das últimas décadas. As preocupações com o meio ambiente, ficaram mais evidentes devido aos crescentes números de atividades desenvolvidas pelo homem nos diversos setores da sociedade (BORGES; TACHIBANA, 2005).

A Educação Ambiental (EA), surgiu com a intenção de levar a sociedade de modo formal e não-formal uma educação direcionada para os indivíduos e a coletividade, onde, os mesmos devem, através dos conhecimentos obtidos por meio dela, desenvolver uma compreensão crítica e global do meio ambiente, aplicando tais ensinamentos no seu dia a dia, no intuito de colaborar com a conservação ambiental, a melhoria da qualidade de vida, e com a eliminação do consumo desenfreado (MEDINA, 2000).

A Educação Ambiental deve ser compreendida como um processo de consciência a partir da análise da realidade regional, de modo que venha permitir o estabelecimento de um compromisso entre a relação da sociedade com a natureza. Ela (EA) possui um caráter social e afeta a estrutura política, econômica e cultural da sociedade, desenvolvendo um elo entre a forma de analisar as problemáticas ambientais e as questões referentes ao meio (RUBIO, 2013).

As instituições de ensino possuem um dos papéis mais importantes na implantação da EA, pois a estas coube o papel de informar, pesquisar e dar formação a sociedade (REIS; MORAIS, 2009). A escola deve oferecer os meios necessários para que os educandos compreendam os fenômenos da natureza, e as possíveis consequências que as ações humanas podem causar no meio natural, tanto para si mesmos, quanto para os outros seres vivos (REIS; MORAIS, 2009). 
Bezerra, Feliciano e Alves (2008) mencionam que ocorre a percepção ambiental por parte dos sujeitos, a partir da tomada de consciência e de compreensão do conjunto. Já o senso comum, para os referidos autores, nasce da percepção direta que as pessoas possuem umas das outras e também das coisas.

Ter o conhecimento das representações de meio ambiente, e saber observar as relações que os indivíduos mantêm com os espaços que ocupam, pode ser considerado o ponto de partida para situar os problemas que o meio ambiente vem sofrendo. Neste sentido pode-se dizer, que a percepção ambiental deve ser entendida como uma tomada de consciência por parte das pessoas, das problemáticas ligadas ao ambiente onde elas habitam, ou seja, é o ato de perceber o lugar (o ambiente) em que nos encontramos inseridos (SILVEIRA; BALDIN, 2016).

Em relação as atividades minerárias, estas, podem provocar diversos efeitos danosos no equilíbrio dos ecossistemas. Dentre estes efeitos, podemos citar a supressão de vegetação, a retirado do solo subsuperficial que possui maior fertilidade, prejuízos as águas dos rios e reservatórios, poluição do ar por particulados em suspensão, vibrações no solo devido à operação de equipamentos e explosões (MECHI; SANCHES, 2010).

Tendo em vista que a Educação Ambiental é um tema que está inserido no currículo das escolas brasileiras de forma transversal junto as outras propostas presentes nos Parâmetros Curriculares Nacionais (BRASIL, 2000), documento este que serve de referência para o Ensino Básico no Brasil, apoiado na Lei de Diretrizes e Bases da Educação (BRASIL, 1996), é que o presente artigo tem por objetivo, analisar a percepção dos discentes do curso técnico integrado em mineração do Instituto Federal do Amapá, campus Macapá, sobre a Educação Ambiental.

\section{Fundamentação Teórica}

\section{Educação Ambiental}

A questão ambiental apresenta-se renovada, pois caracteriza-se por diferentes e novas abordagens. Neste sentido, tem-se uma preocupação fundamental com as questões ambientais na medida em que torna-se crescente a degradação de forma irracional do meio ambiente, vindo a afetar negativamente a qualidade de vida das pessoas, além de colocar em risco as futuras gerações (AMADO, 2017).

De acordo com Gregori e Araújo (2013), o estabelecimento do pensamento humano no qual enxerga a natureza apenas como provedora de recursos, e o ser humano separado dela, isto é, vivendo em um "mundo paralelo", o mundo das ideias, viabilizou a atual crise ambiental, por qual vem passando o planeta. 
Assim, não se pode desvincular a questão ambiental de uma reflexão ampla em torno dos fatores que, ao longo da história contribuíram para a formação de uma cultura que a todo custo pretende o domínio sobre o meio ambiente. Tal reflexão deve ser crítica em relação às epistemologias que difundem a separação entre homem e natureza (GREGORI; ARAÚJO, 2013).

A Educação Ambiental nasceu no surgimento dos movimentos ecológicos do final dos anos 1960 e início dos anos de 1970, quando nos Estados Unidos das Américas inicia-se um forte movimento de ambientalistas, que provocou na opinião pública um posicionamento renovado acerca das questões ambientais (RAMOS, 1996).

No entanto, ainda de acordo com Ramos (1996), apesar da existência de importantes propostas de Educação Ambiental como projeto educativo anteriormente a década de 1970, foi com a Conferência das Nações Unidas sobre o Meio Ambiente Humano, realizada em Estocolmo no ano de 1972, que se teve o primeiro pronunciamento oficial sobre a necessidade da difusão da Educação Ambiental em escala mundial.

Esses movimentos expuseram as necessidades de conscientizar as pessoas em relação a finitude que os recursos da natureza apresentam, e também que a sociedade mundial venha cada vez mais adotar o princípio da racionalidade na utilização dos recursos, considerando que a proteção dos recursos naturais e o crescimento econômico não devem ser vistos de forma antagônicos, tendo em vista a possibilidade de se aliar os dois (RAMOS, 1996).

No Brasil, a verdadeira expressividade da EA foi celebrada com a publicação da Lei no 9.795 de 27 de abril de 1999, que dispôs sobre a Política Nacional de Educação Ambiental (BRASIL, 1999), colocando-a como "um componente essencial e permanente da educação nacional, que deve estar presente, de forma articulada, em todos os níveis e modalidades do processo educativo, em caráter formal e não-formal".

O conceito de EA está definido no artigo $1^{\circ}$ da Política Nacional de Educação Ambiental, onde a mesma é entendida como:

processos por meio dos quais o indivíduo e a coletividade constroem valores sociais, conhecimentos, habilidades, atitudes e competências voltadas para a conservação do meio ambiente, bem de uso comum do povo, essencial à sadia qualidade de vida e sua sustentabilidade (BRASIL, 1999).

O parágrafo $2^{\circ}$ do artigo 10 da Política Nacional de Educação Ambiental, determina que a EA não deve ser implantada como disciplina específica no currículo de ensino, mas trabalhada de forma articulada nos diversos componentes curriculares que compõem o currículo escolar (BRASIL, 1999). 
No mesmo sentido preceitua a Lei de Diretrizes e Bases da Educação Brasileira em seu artigo 26, parágrafo $7^{\circ}$, que diz que: "Os currículos do ensino fundamental e médio devem incluir os princípios da proteção e defesa civil e a Educação Ambiental de forma integrada aos conteúdos obrigatórios" (BRASIL, 1996).

Portanto, a Educação Ambiental é um tema que está inserido no currículo das escolas brasileiras de forma transversal, não sendo considerada uma disciplina específica, mas, que deve ser aprofundada em todas as áreas do conhecimento, junto a outras propostas nos Parâmetros Curriculares Nacionais, devendo ocorrer nos diferentes espaços educativos, de maneira formal ou não-formal (RIBEIRO; LOGAREZZI, 2015).

\section{Mineração no Estado do Amapá}

A ocupação histórica do Estado do Amapá tem mostrado sua vocação natural para a atividade extrativa mineral, pois sua formação social e econômica teve em grande parte vínculos com a mineração, que teria sido inaugurada de acordo com alguns registros ainda no século XVII, devido o interesse de estrangeiros que aqui desembarcaram em busca de ouro e outras riquezas minerais (IEPA, 2010).

Dois séculos mais tarde, de acordo com o Instituto de Pesquisas Científicas e Tecnológicas do Estado do Amapá (IEPA, 2010), mais precisamente em 1893 foi descoberta uma grande quantidade de ouro na área conhecida como garimpo do Lourenço, na região central do Estado, que se consolidou mais tarde como um importante polo garimpeiro no Amapá.

Já em meados do século XX, foi implantado no Estado o primeiro grande empreendimento mineral da Amazônia, o projeto Indústria e Comércio de Minérios S/A (ICOMI), que explorou o minério de manganês encontrado em grandes depósitos na região de Serra do Navio. Após esse importante acontecimento, houve uma diversificação extrativa no Estado, vindo a ser instalado grandes projetos industriais para a extração de caulim, cromita, ouro e, minério de ferro (IEPA, 2010).

Conforme o lepa (2010), a tradição da mineração no Estado do Amapá, tem perdurado até os dias atuais, pois nos últimos anos, ocorreram vários estudos geológicos que confirmam a riqueza no subsolo amapaense, apontando as potencialidades de exploração. Assim, as pesquisas em mineração no Amapá têm despertado o interesse de grupos empresariais, tanto nacionais quanto estrangeiros, que encontram no Estado as condições ideais para investimentos futuros.

A atividade de mineração na Amazônia gerou crescimento econômico para as empresas, mas sem favorecer o desenvolvimento social das comunidades envolvidas, principalmente em longo prazo. Ao contrário, estes empreendimentos desprezaram a economia local, fizeram alteração na 
estrutura espacial, causaram degradação no meio ambiente e acabaram atraindo imigrantes para próximo de si (SIMÕES, 2009).

Simões (2009) menciona ainda que o Estado do Amapá foi por duas vezes surpreendido com a paralisação de atividades e saída de mineradoras antes do tempo previsto para o término de exploração das áreas, a exemplo da ICOMI, que desenvolveu suas atividades em Serra do Navio, e também da Mineradora Pedra Branca do Amapari (MPBA), no Município de Pedra Branca do Amapari.

\section{Impactos Ambientais da Mineração}

A mineração pode causar diversos impactos ao meio ambiente. Os grandes problemas causados pelas ações antrópicas das mineradoras podem ser: a remoção do solo superficial que possui maior taxa de fertilidade, deixando os solos remanescentes sujeitos aos processos erosivos, o que pode vir a ocasionar o fenômeno denominado de assoreamento dos corpos hídricos que ficam no entorno da área de mineração; prejuízos a qualidade das águas dos rios e reservatórios da bacia hidrográfica, a jusante do empreendimento, em razão da turbidez provocada pelos sedimentos finos em suspensão, assim como pela poluição causada por substâncias lixiviadas e carreadas ou contidas nos efluentes das áreas de mineração, como óleos, graxas, e metais pesados, podendo tais substâncias atingir inclusive as águas subterrâneas (MECHI; SANCHES, 2010).

Ainda de acordo com Mechi e Sanches (2010) as atividades desenvolvidas pela mineração podem causar:

com frequência, a poluição do ar por particulados suspensos pela atividade de lavra, beneficiamento e transporte, ou por gases emitidos da queima de combustível. Outros impactos ao meio ambiente estão associados a ruídos, sobrepressão acústica e vibrações nos solos, associados à operação de equipamentos e explosões.

Silva (2007) menciona que a atividade exploratória da mineração expõe a comunidade aos grandes ruídos provocados pelo desmonte de material consolidado, como os maciços rochosos e terrosos, que são muito compactados. Estes ruídos são causados por explosivos, o que resulta em prejuízos à tranquilidade pública, gerando também impactos à fauna local. Pontes, Farias e Lima (2013), complementam que além dos efeitos dos ruídos ocasionados pelo uso de explosivos, estes podem expor os trabalhadores à grandes riscos de acidentes, podendo ocasionar inclusive mortes. 
Bitar (1997) menciona que a atividade de mineração é a grande responsável por promover diversos efeitos indesejados, onde, segundo o autor, os impactos de grande relevância seriam as alterações no meio ambiente, conflitos de uso do solo, a depreciação de imóveis próximos aos empreendimentos, transtornos ao tráfego urbano e a geração de áreas degradadas. Com o surgimento destes efeitos, passam a existir também, os conflitos com a comunidade, pois, em muitos casos as empresas não tem interesse em atender as necessidades da população afetada.

Essa atividade pode causar também problemas com a sociedade, tais como a apropriação de terras, problemas na saúde da população e na infraestrutura urbana, além da migração de pessoas para próximo destes empreendimentos (SIMÕES, 2009).

\section{O Curso Técnico Integrado em Mineração}

O Estado do Amapá possui forte vocação para a atividade de mineração (IFAP, 2012), no entanto, de acordo com o Diagnóstico do Setor Mineral do Estado do Amapá, um dos maiores gargalos ao desenvolvimento do setor no Estado, é a falta de profissionais com formação adequada ao perfil demandado pelas empresas (IEPA, 2010).

Percebendo esta demanda, e após proceder as pesquisas e informações oriundas do mercado de trabalho regional e nacional, o Instituto Federal do Amapá, propôs-se a oferecer o curso Técnico em Mineração na modalidade presencial (IFAP, 2012). O curso objetiva formar profissionais aptos a realiza atividades de prospecção, avaliação técnica e econômica, planejamento e extração de recursos minerais, operando equipamentos de extração, sondagem, perfuração, amostragem e de transporte (MEC, 2016).

Esses profissionais têm como campo de atuação as empresas de mineração e de petróleo, de equipamentos, consultoria e os centros de pesquisa do setor mineral (MEC, 2016).

\section{Metodologia}

O estudo foi realizado no Instituto Federal do Amapá, campus MacapáAP, a amostra da pesquisa foi constituída por estudantes do curso Técnico em Mineração na modalidade Integrada. Participaram da pesquisa 37 estudantes de ambos os sexos, sendo $16(43,2 \%)$ do sexo masculino e $21(56,8 \%)$ do sexo feminino, todos concluintes e que estavam regularmente matriculados no ano letivo de 2017, com idade entre 17 e 20 anos.

Os dados foram obtidos por meio de aplicação de questionário online, através da utilização da ferramenta google forms, um serviço da empresa Google que fornece formulários, editores de textos, planilhas, apresentações e desenhos. 
O referido questionário utilizado para a coleta dos dados desta pesquisa foi construído a partir da obtenção de questões publicadas anteriormente, e que constam das obras dos seguintes autores, que tratam do tema discutido neste trabalho: Reis e Morais (2009) - Educação Ambiental no curso técnico em edificações do proeja: percepção dos alunos quanto a influência da disciplina no seu comportamento ambiental; Silva e Marchetto (2015) - A Percepção da Educação Ambiental no Ensino de Jovens e Adultos - EJA Escola Estadual Antônio Aggio - São Paulo, Capital; Bennemann e Grzebieluckas (2016) - Consciência ecológica dos discentes do Curso de Ciências Contábeis da UNEMAT: uma análise dos hábitos e práticas ambientais; Santos, Lopes e Júnior (2017) - Percepção ambiental dos estudantes do ensino técnico em agropecuária do Instituto Federal de Educação, Ciência e Tecnologia Baiano em relação à Educação Ambiental e a sua importância para a formação profissional.

Para a coleta dos dados, os alunos foram direcionados para 0 Laboratório de Informática, onde foram orientados acerca do preenchimento do questionário da pesquisa e do Termo de Consentimento Livre e Esclarecido (TCLE). Os dados coletados durante a pesquisa foram analisados $e$ sistematizados no software livre Libre Office 5.3.

\section{Resultados e Discussões}

Inicialmente buscou-se saber, junto aos estudantes, qual é o principal setor responsável pelos danos causados ao meio ambiente? Os resultados revelaram (Figura 1) que a maioria dos estudantes $62,2 \%$ consideram as indústrias como as principais responsáveis pelos danos causados ao meio ambiente. No entanto, parte dos alunos $24,3 \%$ consideram o setor agrícola como o principal responsável por danos causados à natureza. Já $8,1 \%$ considera a sociedade e $5,4 \%$ consideram o governo, como os principais causadores de danos.

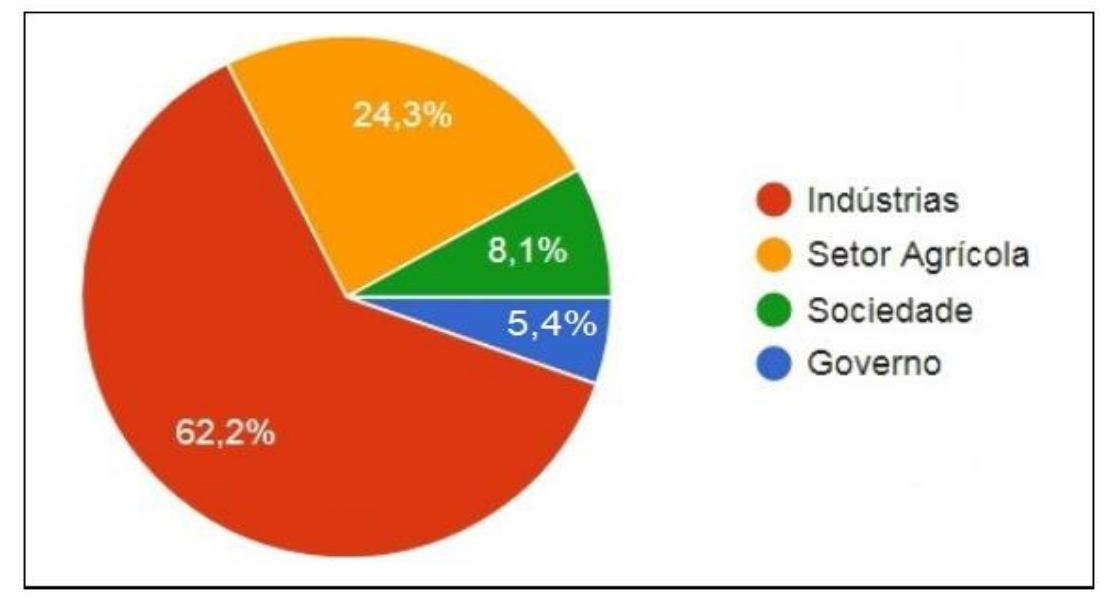

Figura 1: Percepção dos estudantes do curso Técnico em Mineração sobre, qual é o principal setor responsável pelos danos causados ao meio ambiente. Fonte: Dados da pesquisa. 
Em estudo análogo verificado em Santos, Lopes e Júnior (2017) observou-se que os estudantes pesquisados pelos autores, consideraram a sociedade como a principal causadora dos danos ambientais, mostrando que os mesmos possuem uma percepção ambiental diferente da revelada pelos dados obtidos nesta pesquisa, onde para $23(62,2 \%)$ estudantes do curso de mineração, as indústrias são as principais responsáveis pelos danos causados ao meio ambiente.

Verifica-se que os estudantes pesquisados por Santos, Lopes e Júnior (2017), ao considerarem a sociedade como a principal causadora dos danos ambientais, têm-se uma resposta dos mesmos, mais voltada para a vertente conservacionista da EA, pois de acordo com tal vertente o ser humano e o grande responsável pela destruição da natureza. Essa vertente propõe a conservação e a preservação da natureza independente do contexto social e político, preocupando-se com os ambientes naturais e sua preservação, assim, o ser humano é tratado somente como um mero destruidor da natureza, sem qualquer conotação social (LAYRARGUES; LIMA, 2014).

Já os alunos de mineração ao considerarem as indústrias como sendo as principais responsáveis pelos danos causados ao meio ambiente, estão indo ao encontro do que diz a vertente da EA denominada de crítica, também chamada de transformadora, popular, emancipatória ou dialógica. Esta vertente, objetiva analisar a partir de uma visão socioambiental, política e econômica, que os problemas da ecologia são reais e já estão presentes há muito tempo, tal vertente diz que o modus operandi do próprio sistema de capital é quem é o causador dos pretéritos e atuais problemas socioambientais. Neste sentido, a vertente crítica também objetiva mudanças, mas não de alguns setores, mas sim a criação de uma nova sociedade, pois é totalmente contra o sistema capitalista vigente (SANTOS; TOSCHI, 2015).

No entanto, o governo é o que menos tem responsabilidade por tais danos de acordo com o estudo de Santos, Lopes e Júnior (2017), fato esse também demonstrado neste trabalho onde para, 5,4\% dos alunos o governo, é o que menos tem responsabilidade por danos contra o meio ambiente. Assim, acredita-se que o Governo é considerado como o que menos tem responsabilidade por danos ambientais na percepção dos estudantes, justamente por ser ele um dos principais atores que deve atuar na proteção ambiental que é exercida por meio do poder de polícia ambiental através de suas instituições, a exemplo do Instituto Brasileiro do Meio Ambiente e dos Recursos Naturais Renováveis (IBAMA) no âmbito da União (AMADO, 2017).

Quando perguntados (Figura 2) qual setor é mais envolvido com a proteção do meio ambiente? Obteve-se que $37,8 \%$ dos discentes afirmaram ser o governo quem mais se envolve nessa causa. 


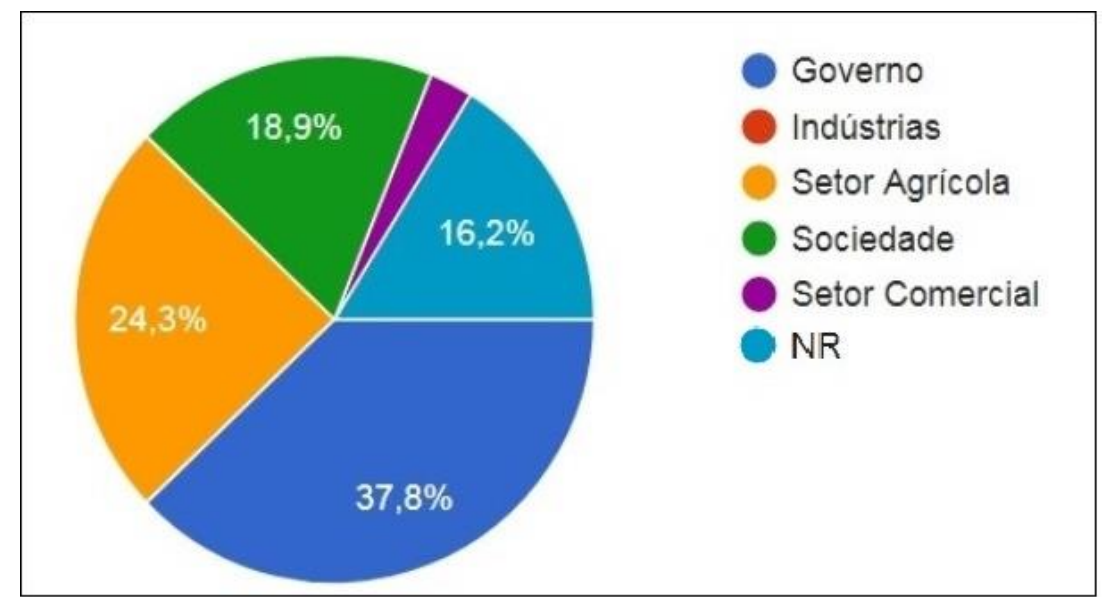

Figura 2: Percepção dos estudantes do curso Técnico em Mineração sobre, qual setor é mais envolvido com a proteção do meio ambiente. Fonte: Dados da pesquisa.

O Amapá, possui uma área significativa que estar sob regime especial de proteção, onde, mais de $70 \%$ do seu território está protegido em forma de unidades conservação e terras indígenas. Tais áreas perfazem um total de dez milhões de hectares sob proteção (SEMA, 2016). O Estado possui uma área territorial de aproximadamente $143 \mathrm{mil} \mathrm{km}^{2}$, onde, diversos ecossistemas compõem a sua biodiversidade, tais como os ecossistemas de mangues, campos, campinas, serrados, florestas de terra firme, florestas de várzea e florestas de igapó, que representam juntos um dos mais importantes recursos para promoção do desenvolvimento social e econômico do Estado. Nesta perspectiva, verifica-se a importância que o Governo (Federal e Estadual) tem dado a essas áreas ao instituí-las como áreas protegidas, tornando o Amapá o Estado mais preservado da Amazônia e do Brasil, com aproximadamente 95\% da sua área em estado de conservação (DIÁRIO DO AMAPÁ, 2017).

No estudo realizado por Santos, Lopes e Júnior (2017), os estudantes consideraram o setor agrícola como o mais envolvido com a proteção ambiental, o que não ficou muito distante da percepção dos alunos que participaram desta pesquisa, onde os mesmos consideram em sua maioria o Governo como sendo o mais envolvido com a proteção da natureza, seguido pelo setor agrícola.

Verifica-se portanto, através da análise da percepção dos discentes do curso de mineração do IFAP, que a maioria dos mesmos dão crédito ao Governo, ao dizerem ser este o setor que mais é envolvido com a proteção do meio ambiente, e tal crédito pode estar atrelado ao fato de o Amapá ser 0 Estado mais preservado do Brasil.

Tal percepção se alinha ao que preconiza a Constituição Federal de 1988 que estruturou uma composição tutelar dos valores ambientais, reconhecendo-Ihes características próprias, que são desvinculadas dos institutos da posse e da propriedade, ficando evidente através do seu artigo 
225, o qual menciona que o Poder público (Governo) e a sociedade devem defender e preservar o meio ambiente para as presentes e futuras gerações (FIORILLO; MORITA; FERREIRA, 2015).

Já para $24,3 \%$ dos discentes pesquisados quem mais é envolvido com a proteção do meio ambiente e o setor agrícola, esta percepção está de acordo com dados levantados pela Empresa Brasileira de Pesquisas Agropecuárias (EMBRAPA), que foram coletados através da incorporação da base de dados do Cadastro Ambiental Rural (CAR) do Serviço Florestal Brasileiro (SFB) ao Sistema de Inteligência Territorial Estratégica (SITE) do Grupo de Inteligência Territorial Estratégica (GITE), que mostraram que a agricultura tem tido papel de destaque na preservação ambiental.

De acordo com cálculos do GITE da Embrapa, a partir das análises de dados geocodificados do CAR, o setor agrícola possui participação significativa na preservação ambiental. De acordo com os resultados preliminares das análises feitas pelos pesquisadores da instituição, no final de 2016, mais de 170 milhões de hectares de vegetação nativa estavam em estado de preservação pelos agricultores dentro dos imóveis rurais, dados estes que representam mais de $20 \%$ do território brasileiro (EMBRAPA, 2017).

Ainda de acordo com os dados levantados pelo GITE, 47,7\% em média, das áreas dos imóveis rurais são reservadas pelos seus proprietários para a preservação da vegetação nativa e da biodiversidade. O Brasil ainda mantém no total $66,3 \%$ de seu território dedicado à preservação e proteção da vegetação nativa, sendo que um terço desse total, é garantido pelo setor agrícola (EMBRAPA, 2017).

Os discentes também foram indagados sobre qual setor é menos envolvido com a proteção do meio ambiente? A pesquisa revelou que as indústrias com $43,2 \%$ das respostas são as menos envolvidas na proteção do meio ambiente segundo os estudantes, seguida do setor comercial com $24,3 \%$.

A pesquisa apresentou um comportamento semelhante ao que foi verificado no estudo realizado por Santos, Lopes e Júnior (2017), onde, os estudantes afirmaram ser as indústrias o setor menos envolvido com a proteção do meio ambiente.

Este comportamento de acordo com Jabbour e Jabbour (2013) mostra o grande desafio que as indústrias possuem na atualidade, tendo em vista que as mesmas ao buscarem ser mais sustentáveis devem identificar uma forma adequada de gestão das dimensões ambiental e social, de modo a integrá-las aos benefícios econômico-financeiros, uma vez que os clientes buscam cada vez mais comprar de empresas que possuem um comportamento voltado para as responsabilidades ambiental e social.

Em relação ao comércio apontado por $24,3 \%$ dos alunos como sendo o setor menos envolvido com a proteção do meio ambiente, verifica-se que as empresas que atuam neste setor também devem voltar sua preocupação com a questão ambiental pelo fato de seus lucros estarem vinculados ao marketing 
estratégico ambiental, tendo em vista que sua imagem no mercado depende da satisfação dos clientes que buscam cada vez mais organizações ambientalmente sustentáveis (ARAÚJO et al., 2013).

A preservação ambiental é de grande relevância para o profissional da área de mineração, tendo em vista que este profissional tem o papel de desenvolver suas atividades, sem deixar de levar em consideração o desenvolvimento sustentável.

Assim, quando foram questionados se os mesmos tinham por hábito falar sobre a importância da preservação ambiental? $67,6 \%$ dos alunos afirmaram que sim, e $27 \%$ disseram que as vezes falam dessa importância, já $5,4 \%$ disseram que não tem por hábito falar da importância da preservação do meio ambiente.

Neste sentido conforme Bennemann e Grzebieluckas (2016) quando se trata de preservar o meio ambiente a grande maioria dos estudantes tem por hábito falar de sua importância, o que demonstra que há por parte dos mesmos, preocupação em se falar sobre a importância da preservação ambiental no âmbito escolar. No entanto, observa-se que um pequeno grupo de alunos ainda não dão importância a estas questões.

De acordo com Mousinho (2003), embora seja expressivo o número de estudantes comentando com outras pessoas sobre a importância de se preservar o meio ambiente, ainda faz-se necessário despertar a preocupação individual e coletiva para essas questões, com o fim de estimular o interesse em se recuperar os recursos ambientais.

Tal estímulo deve receber atenção por partes dos atores envolvidos na difusão da EA, pois conforme mencionam Freitas e Zaú (2015) os problemas ambientais ocorrem com maior intensidade nos dias atuais, sendo que, para os autores as dificuldades que os discentes apresentam em abordagens que envolvem o homem e a natureza, juntados aos obstáculos que os docentes enfrentam para trabalhar aspectos da EA nas instituições de ensino, fazem com que a temática ambiental apresente grande relevância na atualidade.

A Educação Ambiental é de grande relevância na atualidade, pois incumbe ao poder público promovê-la em todos os níveis de ensino, assim como a conscientização pública para a preservação do meio ambiente (PNEA, 1999). Essa (EA) deve ser desenvolvida como uma prática educativa integrada, contínua e permanente, nas instituições de ensino brasileiras.

Neste sentido foi perguntado aos pesquisados que relevância eles davam ao tema Educação Ambiental? 97,3\% dos estudantes afirmaram que o conhecimento em Educação Ambiental pode fazer a diferença na profissão do técnico em mineração, mostrando a preocupação de tais discentes com a questão ambiental no desenvolvimento das atividades de mineração. Destacase ainda que para $97,3 \%$ dos alunos, a EA é considerada como importante para que o profissional de mineração possa auxiliar a empresa na gestão 
ambiental corporativa. Nesta pergunta os estudantes poderiam escolher duas (02) opções para marcar.

Esse posicionamento dos estudantes e bem relevante, pois, segundo Simões (2009) a atividade de mineração gera fortes impactos no meio ambiente, tais como o desmatamento, o assoreamento de cursos d'água, e a destruição da biodiversidade (Figura 3).

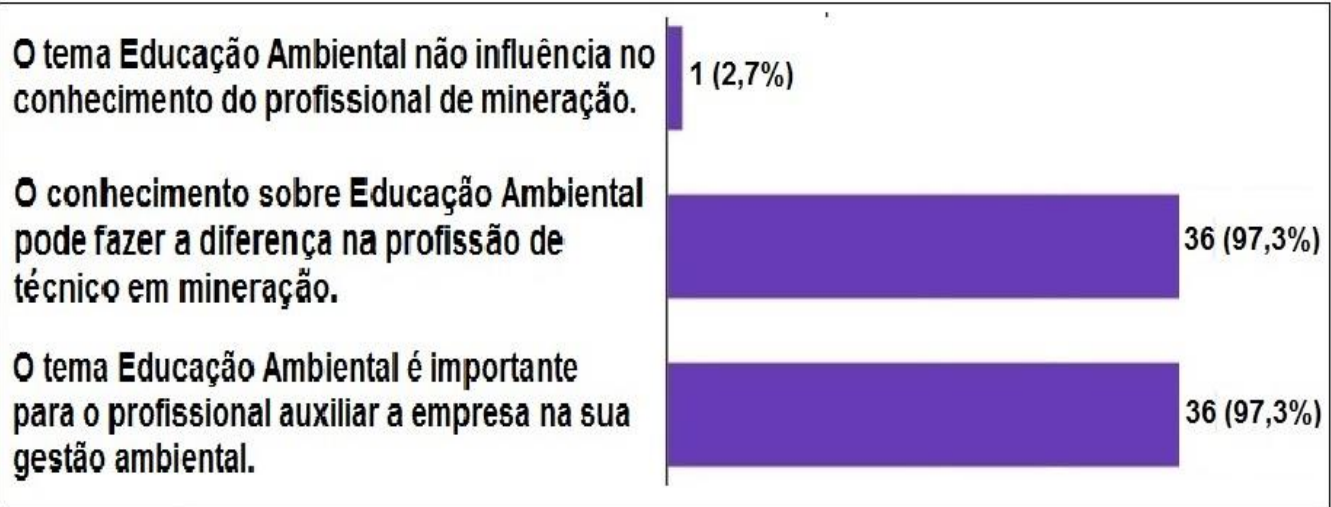

Figura 3: Percepção dos estudantes do curso Técnico em Mineração sobre a relevância dada ao tema Educação Ambiental. Fonte: Dados da pesquisa.

Já, na perspectiva de auxiliar as empresas de mineração na gestão ambiental com os conhecimentos de EA, verifica-se que com o passar dos tempos as organizações pas saram justamente a buscar profissionais comprometidos com a questão ambiental, tendo em vista que uma boa gestão ambiental pode gerar diversos benefícios para as empresas, tais como: a melhoria do desempenho operacional, redução dos custos operacionais, fontes de crédito e financiamento, elevação da reputação corporativa, etc. (JABBOUR; JABBOUR, 2013).

Destaca-se ainda que em estudo semelhante, Bennemann e Grzebieluckas (2016) verificaram que a Consciência ecológica obtida através da Educação Ambiental de discentes de um determinado curso de graduação da Universidade do Estado de Mato Grosso (UNEMAT) é considerada pela grande maioria dos acadêmicos como importante para que um profissional possa ajudar uma organização na sua gestão ambiental.

Quando os discentes foram indagados se já tiveram alguma disciplina que abordou a questão ambiental? $100 \%$ (37 alunos) afirmaram que sim, fato este que demonstra que a Lei de Diretrizes e Bases da Educação Brasileira de 1996, em seu artigo 26, parágrafo $7^{\circ}$, que diz que "os currículos do ensino fundamental e médio devem incluir a Educação Ambiental de forma integrada aos conteúdos obrigatórios" está sendo cumprida na instituição onde foi realizada esta pesquisa.

O quantitativo de $100 \%$ dos alunos objeto desta pesquisa, afirmarem já ter tido disciplina que abordou a questão ambiental, pode ter ocorrido em

Revbea, São Paulo, V. 15, № 1: 288-309, 2020. 
virtude de o curso ter em sua matriz curricular, a disciplina de Meio Ambiente, Saúde e Segurança do Trabalho Aplicada a Mineração, que aborda a questão da mineração e meio ambiente, barragens e depósitos de rejeitos, vibrações, vegetação, e também a questão da recuperação de áreas degradadas, poeiras, ruídos e tratamento da água na mineração, além de abordar a questão do fechamento de mina (IFAP, 2012).

Os discentes pesquisados, também foram indagados se o tema Educação Ambiental abordado durante 0 curso ajudou eles na compreensão sobre as questões ambientais? Os resultados revelaram que para $91,9 \%$ dos estudantes o tema EA ajudou-os sim, a compreender sobre as questões ambientais. Já $8,1 \%$ dos alunos afirmaram que o tema EA não os ajudou na compreensão sobre questões relacionadas ao meio ambiente.

Reis e Morais (2009), verificou que $100 \%$ dos alunos pesquisados por ele, afirmaram que a disciplina EA tem ajudado na compreensão sobre as questões que envolvem o meio ambiente, o que nos mostra um resultado de pesquisa próximo ao obtido junto aos alunos de mineração do IFAP.

Depreende-se portanto, a importância do tema Educação Ambiental inserida no curso, tendo em vista que a mesma, possibilita ao futuro profissional de mineração, ter uma maior percepção e compreensão dos diversos fatores que interferem na qualidade do meio ambiente.

Neste sentido, Silva (2013), menciona que a EA disponibiliza os meios de percepção e compreensão dos diversos fatores que interferem na qualidade ambiental, assim, como também dos seus efeitos sobre o meio ambiente como um todo. Tal Educação, portanto, visa uma mudança de postura por parte do homem para com a natureza, sendo necessário adotar hábitos novos, assim como, comportamentos e valores que promovam a qualidade de vida para todos.

Reis e Morais (2009) verificaram que, para $100 \%$ dos alunos pesquisados do curso de edificações do IFPI, o tema EA possibilita uma melhoria no comportamento ambiental dos alunos como futuros profissionais. No mesmo sentido, apontou os dados da pesquisa levantada no IFAP, junto aos discentes, onde, para 37 (100\%) estudantes, o tema EA possibilita a melhoria do comportamento ambiental dos mesmos, como futuros profissionais que atuarão na área de mineração.

Esses dados nos mostram que a preocupação com o meio ambiente não está presente somente nas organizações, mas também no âmbito da academia, no qual tem-se percebido o surgimento de vários estudos relacionados ao meio ambiente, dando-se destaque a importância de se ministrar o tema EA nos diversos cursos, tendo em vista que as preocupações com as questões ambientais estão tomando maiores proporções na sociedade (BENNEMANN; GRZEBIELUCKAS, 2016).

Quando perguntados de que forma o tema Educação Ambiental possibilitaria essa melhoria do comportamento ambiental dos alunos de 
mineração? a pesquisa revelou (Figura 4) que para 27 (73\%) alunos essa melhoria se daria na ação de reutilização de materiais, para $25(67,6 \%)$ estudantes a melhoria se daria na questão da valorização da reciclagem, para $18,9 \%$ (7 alunos) a melhoria seria na questão de se tornar um multiplicador acerca das questões ambientais, já $6(16,2 \%)$ estudantes a EA possibilitaria a diminuição do consumismo. 7 (18,9\%) alunos, assinalaram a opção outros, o que indica que para eles, outros seriam os motivos que possibilitariam a melhoria do seu comportamento ambiental como profissional de mineração. Nesta pergunta os alunos poderiam marcar duas alternativas como resposta ao questionamento.

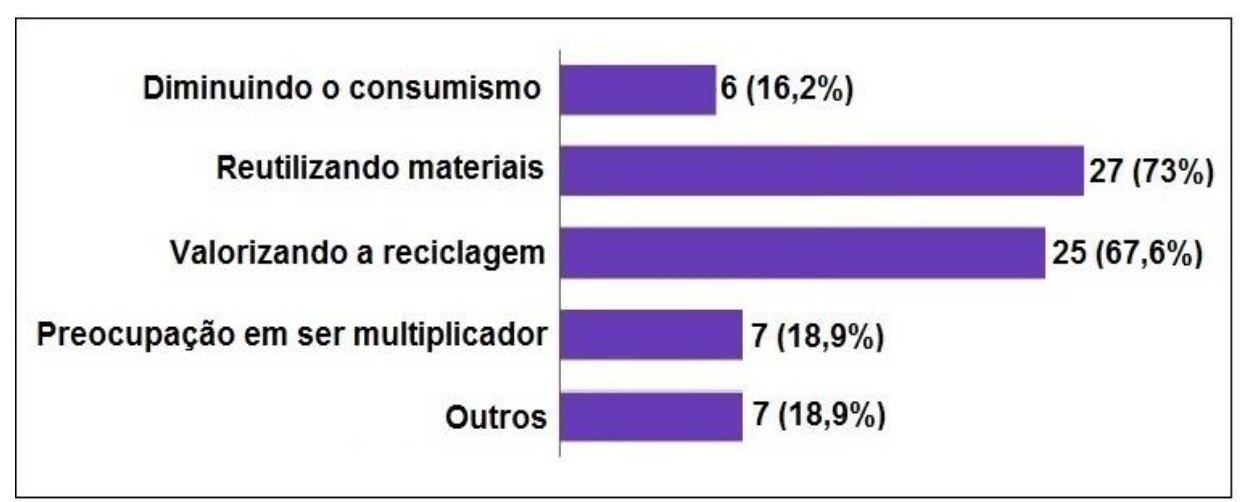

Figura 4: Percepção dos estudantes do curso Técnico em Mineração sobre de que forma o tema Educação Ambiental possibilita a melhoria do comportamento ambiental.

Fonte: Dados da pesquisa.

Em relação a essa melhoria no comportamento ambiental, o estudo realizado por Reis e Morais (2009) apontou que para $45 \%$ dos alunos a melhoria se dá sobre a valorização da reciclagem, para 30\% a possibilidade de reutilização de materiais, já para $20 \%$ dos estudantes, essa melhoria seria na diminuição do consumismo e $5 \%$ dos alunos apontaram outros motivos. Neste estudo os alunos poderiam optar por apenas uma alternativa.

As duas pesquisas nos mostram a forte preocupação dos estudantes com as questões relacionadas a valorização da reciclagem e a possibilidade de reutilização de materiais. Essas práticas são maneiras ambientalmente mais viáveis. Com a reciclagem, os materiais são transformados em matéria-prima para a produção de um novo produto, reduzindo assim a utilização de fontes naturais. Já a reutilização consiste em usar de novo um determinado produto, dando ou não uma nova função para um objeto considerado sem utilidade.

A reutilização e a reciclagem de materiais contribuem para 0 desenvolvimento sustentável, pois tais processos minimizam a geração de resíduos descartados no meio ambiente e o respectivo consumo de matériaprima não renovável. Essas práticas reduzem os impactos ambientais que são causados pela extração de matéria-prima e a disposição final inadequada dos resíduos (BOHNENBERGER et al., 2018). 
Os alunos foram questionados se a atividade de mineração implicava em algum problema ambiental? Os mesmos em sua maioria $97,3 \%$ afirmaram que sim, já 2,7\% dos alunos, disseram que a atividade de mineração não implicava em problemas ambientais.

A posição da maioria coaduna com o que está expresso na literatura acerca dos impactos ambientais que a atividade de mineração causa ao meio ambiente, a exemplo do que menciona Bitar (1997), onde para ele:

essa atividade é a grande responsável por promover diversas alterações no meio ambiente, conflitos de uso do solo, depreciação de imóveis circunvizinhos, transtornos ao tráfego urbano e a geração de áreas degradadas.

O desmatamento e o principal problema ambiental causado pela mineração, sendo que vários são os prejuízos advindos de tal prática, dentre os quais podemos citar: o prejuízo a qualidade das águas; a poluição do ar devido a movimentação de máquinas; a perda de biodiversidade da flora e da fauna local, o que ocasiona desequilíbrio ecológico; e o empobrecimento do solo devido a retirada da vegetação para a extração da matéria-prima mineral (MECHI; SANCHES, 2010).

Pereira, Costa e Borges (2017), no mesmo sentido, consideram que:

as atividades desenvolvidas pelo setor mineral são as grandes geradoras de impactos negativos ao meio ambiente, uma vez que é através da extração de recursos minerais, que se tem a geração de uma série de consequências que degradam uma área ambiental, levando-a a alteração significativa da qualidade do meio físico e do meio biótico, tanto ao nível regional, quanto local.

Em relação ao grau de preocupação dos alunos quanto as questões ambientais, 37,8\% afirmaram ter um grau de preocupação forte, já 56,8\% afirmaram ter grau de preocupação mediano quanto as questões ambientais, e $5,4 \%$ assinalaram grau fraco. Esses dados nos revelam que se deve intensificar ainda mais junto aos estudantes de mineração o ensino da EA, com o objetivo de incentivar e modelar a consciência ambiental desses sujeitos.

Neste sentido aponta Brondani e Henzel (2010) que a preocupação com a preservação do meio ambiente, tem se acentuado nos dias atuais, justamente em função do aumento das atividades desenvolvidas pelo homem, as quais, sob a ótica de obter recursos naturais necessários para produzir bens 
e serviços, têm gerado a crença de que a natureza existe para servir ao ser humano, o que consequentemente tem ocasionado diversos problemas antrópicos ao meio ambiente, comprometendo a disponibilidade de recursos naturais e as condições de vida no planeta.

Quando os alunos foram questionados sobre qual seria a principal fonte de obtenção de informações sobre questões ambientais pelos mesmos, $51,4 \%$ dizem obter tais informações por meio das mídias sociais. Já para 21,6\% tais informações são extraídas de revistas e jornais. Outros 21,6\% dizem que buscam tais informações em sala de aula e 5,4\% obtêm tais informações em outros meios de comunicação.

O trabalho dos temas que envolvem a complexidade ambiental decorrentes das práticas existentes e possibilidades de analisar a realidade de modo complexo, veio para privilegiar o diálogo e a interdependência de diferentes áreas do conhecimento, principalmente através das redes sociais, e das veiculações de informações pela internet, onde 0 estímulo dos participantes é cada vez mais forte (JACOBI, 2003) (Figura 5).

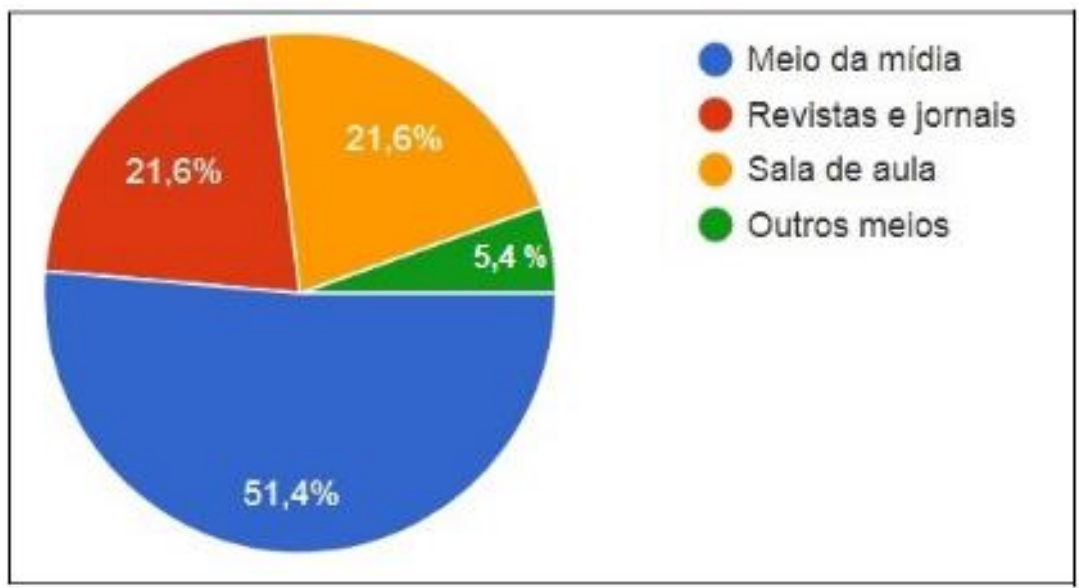

Figura 5: Percepção dos estudantes do curso Técnico em Mineração sobre a principal fonte de obtenção de informações sobre questões ambientais. Fonte: Dados da pesquisa.

Atualmente vem ocorrendo uma crescente proliferação e abertura de novos espaços de comunicação para a Educação Ambiental, tais como congressos, fóruns, e os meios digitais, percebe-se também a formação de redes e a crescente multiplicação de sítios na web, que abordam a temática $E A$, com o intuito de sensibilizar a população acerca dos problemas que afetam o meio ambiente (RODRIGUES; COLESANTI, 2008).

Deste modo, verifica-se, a importância das mídias sociais e da internet no ensino da Educação Ambiental, visto que através destes veículos de informações muitos estudantes podem obter seus conhecimentos acerca desta temática. 
Já quando os estudantes foram perguntados se nas abordagens dos temas ambientais, discutidos em sala de aula, deveria ser envolvido a comunidade que reside ao redor da escola? $86,5 \%$ dos alunos assinalaram que sim, que a comunidade residente ao redor do IFAP deveria ser envolvida nas discussões relacionadas aos temas ambientais. 5,4\% dos estudantes disseram que não e $8,1 \%$ assinalaram não saber se a comunidade deveria ser envolvida em tais discussões.

Resultado semelhante verificou-se em Silva e Marchetto (2015), onde para a maioria dos estudantes pesquisados, as abordagens dos temas ambientais, discutidos em sala de aula devem envolver a comunidade ao redor da escola.

Neste sentido, vê-se que a temática ambiental, quando trabalhada de maneira correta nos estabelecimentos de ensino e não ficando restrita apenas aos ambientes escolares, estendendo-se às comunidades, pode contribuir em muito para recuperar e preservar os recursos naturais, melhorando a qualidade de vida da população. Assim, tal situação levaria a sociedade a repensar seus valores, conscientizando-se de que os recursos da natureza não são infinitos e que é possível compreender as inter-relações entre o homem e o meio ambiente (SANTOS, 2007).

Portanto, pode-se dizer que o exercício de uma sociedade participativa nos temas ambientais, pode ser um caminho a ser seguido para que se tenha uma sociedade sustentável, que vise contribuir para uma melhor qualidade de vida no planeta.

\section{Considerações Finais}

O trabalho mostrou que os estudantes, possuem entendimento acerca da dinâmica de interação que ocorre entre o homem e o meio ambiente, e que os mesmos compreendem a importância da Educação Ambiental para sua futura área profissional, tendo em vista que o setor mineral possui potencial de degradação ambiental. A pesquisa revelou que as indústrias são as principais responsáveis pelos danos causados a natureza. Verificou-se também, que o setor que mais é envolvido com a proteção do meio ambiente é o governo.

$\mathrm{Na}$ percepção da maioria dos estudantes, o conhecimento acerca da temática, meio ambiente, e o hábito de falar sobre a importância da preservação ambiental pode fazer a diferença na sua profissão, pois o profissional da área de mineração deve desenvolver suas atividades, levando em consideração a dimensão do desenvolvimento sustentável, além de contribuir na gestão ambiental da empresa em que estiver atuando.

A pesquisa evidenciou que a temática ambiental é desenvolvida de forma transversal na instituição, conforme recomenda a legislação vigente. $E$ na percepção dos discentes a EA abordada durante o curso, ajudou-os na compreensão das questões ambientais, assim como, a mesma proporcionará 
ao futuro profissional de mineração um melhor entendimento acerca dos diversos fatores que interferem na qualidade do meio ambiente. Esse progresso, se daria através de ações que englobam a reutilização de materiais, a valorização da reciclagem e a multiplicação da Educação Ambiental.

No entendimento dos discentes, os temas ambientais discutidos em sala de aula, devem envolver a comunidade que reside ao redor da escola, pois, uma vez colocada em prática, a EA pode contribuir para a preservação dos recursos naturais, recuperação de ambientes alterados e a melhoria da qualidade de vida da população.

\section{Referências Bibliográficas}

AMADO, F. Direito Ambiental. - $8^{\mathrm{a}}$ ed. rev., atual. e ampl. - Salvador: Juspodivm, 2017.

ARAÚJO, A. C.; MATSUOKA, E. M.; UNG, J. E.; HILSDORF, W. C.; SAMPAIO, $M$. Logística reversa no comércio eletrônico: um estudo de caso. Gest. Prod., São Carlos, v. 20, n. 2, p. 303-320, 2013.

BENNEMANN, G.; GRZEBIELUCKAS, C. Consciência ecológica dos discentes do Curso de Ciências Contábeis da UNEMAT: uma análise dos hábitos e práticas ambientais. Rev. Eletrônica Mestr. Educ. Ambient. v. 33, n.2, p. 419, maio/ago., 2016

BezerRA, T. M. O.; Feliciano, A. L. P.; ALVES, A. G. C. Percepção ambiental de alunos e professores do entorno da Estação Ecológica de Caetés - Região Metropolitana do Recife-PE. Biotemas, v. 21, n. 1, p 147-160, Mar. 2008.

BRASIL. Ministério da Educação e Desporto. Diretrizes e bases da educação nacional, lei no. 9.394 de 20 de dezembro de 1996, atualizada até março de 2017. Senado Federal, Coordenação de Edições Técnicas, 2017. Disponível em: <http://www2.senado.leg.br>. Acesso em: 12 maio 2018.

BRASIL. Lei no 9.795/1999 - Dispõe sobre a Educação Ambiental, institui a Política Nacional de Educação Ambiental e dá outras providências. Disponível em: <http://www.planalto.gov.br/ccivil 03/leis/L9795.htm>. Acesso em: 29 out. 2017.

BRASIL. Ministério da Educação. Secretaria de Educação Média e Tecnológica. Parâmetros Curriculares Nacionais (Ensino Médio). Brasília: MEC, 2000. Disponível em: <http://portal.mec.gov.br/expansao-da-redefederal/195-secretarias-112877938/seb-educacao-basica-2007048997/12598publicacoes-sp-265002211 >. Acesso em: 07 nov. 2017.

BITAR, O. Y. Avaliação da recuperação de áreas degradadas por mineração na região metropolitana de São Paulo. 1997. 185f. Tese (Doutorado). Escola Politécnica da Universidade de São Paulo. 1997. 
BRONDANI, C. J.; HENZEL, M. E. Análise sobre a conscientização ambiental em escolas da rede municipal de ensino. Revista Brasileira de Educação Ambiental. v. 5 (2010).

BOHNENBERGER, J. C.; PIMENTA, J. F. P.; ABREU, M. V. S.; COMINI, U. B.; CALIJURI, M. L.; MORAES, A. P.; PEREIRA, I. S. Identificação de áreas para implantação de usina de reciclagem de resíduos da construção e demolição com uso de análise multicritério. Ambiente Construído, Porto Alegre, v. 18, n. 1, p. 299-311, jan./mar. 2018.

BORGES, F. H.; TACHIBANA, W. K. A evolução da preocupação ambiental e seus reflexos no ambiente dos negócios: uma abordagem histórica. Anais do XXV Encontro Nac. de Eng. de Produção - Porto Alegre, RS, Brasil, 29 out a 01 de nov de 2005. Disponível em: <www.abepro.org.br/biblioteca /ENEGEP2005 Enegep1005 1433.pdf>. Acesso em: 18 jun. 2018.

DIÁRIO. Jornal Diário do Amapá. Amapá tem 95\% do seu ecossistema preservado. Disponível em: <https://www.diariodoamapa.com.br/ cadernos/cidades/>. Acesso em: 12 maio 2018.

EMBRAPA. Empresa Brasileira de Pesquisa Agropecuária. Agricultura tem papel de destaque na preservação ambiental, mostra estudo, 2017. Disponível em: <https://www.embrapa.br/busca-de-noticias/>. Acesso em: 13 maio 2018.

FREITAS, J. R. S.; ZAÚ, A. S. Educação Ambiental a partir da interação entre a sala de aula e arredores da comunidade. Revbea, São Paulo, v. 10, № 2: 249269, 2015.

FIORILLO, C. A. P.; MORITA, D. M.; FERREIRA, P. Licenciamento Ambiental. $2^{\mathrm{a}}$ ed. Rev., atual. e ampl. - São Paulo: Saraiva, 2015.

GREGORI, M. S.; ARAUJO, L. E. B. Epistemologia Ambiental: a crise ambiental como uma crise da razão. Revista Eletrônica do Curso de Direito - UFSM, Santa Maria. Edição Especial, v.8, p. 700-711, 2013.

IFAP. Instituto Federal de Educação, Ciência e Tecnologia do Amapá. Plano de curso de nível médio em mineração na forma integrada, 2012. Disponível em: <http://siteantigo.ifap.edu.br//>. Acesso em: 19 dez. 2017.

IEPA. Diagnóstico do setor mineral do Estado do Amapá/coordenador, Marcelo José de Oliveira. Macapá: lepa, 2010. Disponível em: $<$ http://www.mme.gov.br/documents/1138775/1732815/Diagn\%C3\%B3stico+do +Setor+Mineral+do+Estado+do+Amap\%C3\%A1/baf8b84f-2fa5-4b6e-91c0ee8bdad01e63?version=1.0 >. Acesso em: 23 jan. 2018.

JABBOUR, A. B. L. S.; JABBOUR, C. J. C. Gestão ambiental nas organizações: fundamentos e tendências. São Paulo: Atlas, 2013.

JACOBI, P. Educação Ambiental, cidadania e sustentabilidade. Cadernos de

Pesquisa, n. 118, p. 189-205, 2003. 
LAYRARGUES, P. P.; LIMA, G. F. C. As macrotendências político-pedagógicas da Educação Ambiental brasileira. Ambiente \& Sociedade. São Paulo v. XVII, n.1, p. 23-40, jan.-mar. 2014.

MOUSINHO, P. G. In: Trigueiro, A. (Coord.). Meio ambiente no século 21. Rio de Janeiro: Sextante. 2003.

MEC. Ministério da Educação. Catálogo nacional de cursos técnicos, 2016. Disponível em: <http://sitesistec.mec.gov.br>. Acesso em: 19 dez. 2017.

MEDINA, N. M. A formação dos professores em Educação Ambiental. BRASIL. Ministério da Educação (MEC). Panorama da Educação Ambiental no Ensino Fundamental. Brasília, MEC, 2000. Disponível em: $<$ http://www.aedmoodle.ufpa.br/mod/resource/view.php?id=104765 $>$. Acesso em: 27 dez. 2017.

MECHI, A.; SANCHES, D. L. Impactos ambientais da mineração no Estado de São Paulo. Estudos Avançados v.24 (68), 2010.

PONTES, J. C.; FARIAS, M. M. S.; LIMA, V. L. A. Mineração e seus reflexos socioambientais: estudos de impactos de vizinhança (eiv) causados pelo desmonte de rochas com uso de explosivos. Polemica, v.12, n.1, pp.77-90. 2013.

PEREIRA, A. A. S.; COSTA, D. A. T.; BORGES, L. A. C. Percepção ambiental de pós-graduandos sobre os impactos da mineração. Rev. Eletrônica Mestrado Educação Ambiental. Rio Grande, v. 34, n. 2, p. 238-255, maio/ago. 2017.

REIS, L.; MORAIS, M. Educação Ambiental no curso técnico em edificações do proeja: percepção dos alunos quanto a influência da disciplina no seu comportamento ambiental, 2009. Disponível em: <http://www.senept.cefetmg.br/galerias/Anais 2010/Posteres/GT06/EDUCACA O AMBIENTAL.pdf >. Acesso em: 25 set. 2017.

RUBIO, J. L. A. Estrategias para la Educación Ambiental y capacitación para el desarrolho sustentable, 2013. Disponível em: $<$ http://www.uv.mx/iiesca/files/2013/01/ambiental1996.pdf>. Acesso em: $10 \mathrm{de}$ out. 2017.

RAMOS, E. C. Educação Ambiental: evolução histórica, implicações teóricas e sociais. Uma avaliação crítica. 1996.147 f. Dissertação (Mestrado e Educação)- Curso de Pós-Graduação em Educação, Universidade Federal do Paraná, Curitiba, 1996.

Disponível em:<https://acervodigital.ufpr.br/bitstream/handle/1884/29517/D\%20\%20ELISA BETH\%20CHRISTMANN\%20RAMOS.pdf?sequence=1 >. Acesso em: $13 \mathrm{dez}$. 2017.

RODRIGUES, G. S. S. C.; COLESANTI, M. T. M. Educação Ambiental e as novas tecnologias de informação e comunicação. Sociedade \& Natureza, Uberlândia, p.51-66, 2008. 
RIBEIRO, C. L.; LOGAREZZI, A. J. M. Educação Ambiental crítica no contexto da educação de pessoas jovens e adultas: entre o descompasso e o desafio de transformação socioambientais. AmbientalMente sustentable: Revista científica galego-lusófona de educación ambiental, ํㅡ. 20, 2015.

SANTOS, A. M.; LOPES, E. R. N.; JÚNIOR, M. F. S. Percepção ambiental dos estudantes do ensino técnico em agropecuária do Instituto Federal de Educação, Ciência e Tecnologia Baiano em relação à Educação Ambiental e a sua importância para a formação profissional. Revbea, São Paulo, V. 12, No 2: 136-155, 2017.

SILVEIRA, M. S.; BALDIN, N. Concepções de meio ambiente e Educação Ambiental em estudos de percepção ambiental: o caso de professores que lecionam em escolas públicas localizadas em área de bacia hidrográfica. Rev. Eletrônica Mestr. Educ. Ambient. v. 33, n.1, p. 152-170, jan../abr., 2016.

SANTOS, E. T. A. Educação Ambiental na escola: conscientização da necessidade de proteção da camada de ozônio. 2007. 53 f. Monografia (PósGraduação em Educação Ambiental) - Universidade Federal de Santa Maria, Santa Maria, 2007. Disponível em: <http://jararaca.ufsm.br/websites/ unidadedeapoio/download/elaine07.pdf>. Acesso em: 12 dez. 2017.

SILVA, L. J. C. Estudo da percepção ambiental dos alunos do ensino médio no colégio estadual Manoel de Jesus em Simões Filho, BA. Monografia (Especialização em Gestão Ambiental em Municípios) - Universidade Tecnológica Federal do Paraná, Curitiba, 2013. Disponível em: $<$ http://repositorio.roca.utfpr.edu.br/sspui/bitstream/1/4551/1/MD GAMUNI 2014 2 8.pdf >. Acesso em: 12 dez. 2017.

SIMÕES, H. C. G. Q. A história e os efeitos sociais da mineração no estado do Amapá. PRACS: Revista Eletrônica de Humanidades do Curso de Ciências Sociais da UNIFAP, № 2. Dez. 2009.

SILVA, A. E; MARCHETTO, M. A percepção da Educação Ambiental no ensino de jovens e adultos - EJA Escola Estadual Antônio Aggio - São Paulo, Capital. E\&S - Engineering and Science, 2015.

SILVA, J. P. L. Impactos ambientais causados por mineração. Revista Espaço da Sophia, n. 8, pp.1-13. Nov. 2007.

SEMA. Secretaria de Estado do Meio Ambiente do Amapá. O Amapá planeja - plano de comunicação para as unidades de conservação estaduais. Disponível em: <http://www.sema.ap.gov.br/>. Acesso em: 10 maio 2018. 